\title{
TUBERCULIN REACTIONS IN ANKYLOSING SPONDYLITIS COMPARED WITH THOSE IN OTHER RHEUMATIC DISEASES*
}

\author{
By G. ROBINSON, M.B.
}

Two independent sets of observations made at the Devonshire Royal Hospital have both suggested that tuberculin sensitiveness in cases of spondylitis ankylopoietica tends to excess. The phenomenon has been noted recently during von Pirquet testing of assorted rheumatic patients, and formerly ${ }^{1}$ as part of a study of the disease itself. Moreover, such patients have sometimes been treated by vaccination with a fluid containing autolysed tubercle bacilli (the Ponndorf cutivaccine), whose effects in varying degree of flush, cedema and scaling resemble those of a tuberculin reaction. It was therefore thought desirable to determine whether ankylosing spondylitis is in fact associated with excessive tuberculin sensitiveness.

The background of ascertained fact with regard to tuberculin tests $^{2}$ in so far as it specially affects the results below may be recapitulated as (1) the general positiveness of our population and (2) the lower levels in the young, in females and in wasting disease.

The following procedure was adopted. Von Pirquet tests were performed and read at one, two and ten days by a single observer. Five insertions, made from above down on the volar surface of one forearm, consisted of nought, two, six, seventeen and fifty per cent. Old Tuberculin (Burroughs, Wellcome) in saline. The areas of swelling and flush were measured and noted at each of the three readings, and from the data thus obtained each patient's reaction was assigned to one of six classes-namely, 0 Negative, 1 Very Weak Positive, 2 Weak Positive, 3 Moderate Positive, 4 Strong Positive, 5 Very Strong Positive. Thus the figures 0 to 5 form a von Pirquet index, or rough quantitative estimate of the intensity of tuberculin response suitable for purposes of comparison.

* Received for publication December 15, 1939. 
Table I. shows the results obtained by applying this method of testing to a group of assorted "rheumatics" on the one hand and to a group of ankylosing spondylitics on the other. No case which had ever received tubercle vaccine was included in the series.

TABLE I

\begin{tabular}{cc|c|c|c}
\hline Groups. & & $\begin{array}{c}\text { Number } \\
\text { of Cases. }\end{array}$ & $\begin{array}{c}\text { Average } \\
\text { Age. }\end{array}$ & $\begin{array}{c}\text { Average } \\
\text { vP Index. }\end{array}$ \\
\hline $\begin{array}{llll}\text { Male spondylitis ankylopoietica } \\
\text { Assorted male rheumatics }\end{array}$ & $\ldots$ & 45 & $\begin{array}{c}36 \cdot 6 \\
\mathbf{4 3} \cdot 1\end{array}$ & $\begin{array}{c}\mathbf{3 \cdot 3 3} \\
\mathbf{2 5 7}\end{array}$ \\
\hline
\end{tabular}

The spondylitic group is less prone to the feeblest type of reaction ( 0 and 1$)$, and its index is also weighted by the occurrence of three times the frequency of very strong positives obtained in the control group. The distinction between strong and very strong positives was made on the presence of swelling in addition to flush in the 2 per cent. insertion. In spite of the adverse age difference, the spondylitic index is about 30 per cent. higher than the control index.

The likelihood of this result being due to chance has now to be considered. The frequencies of the six index numbers. for control and spondylitic groups are set out in Table II.

TABLE II

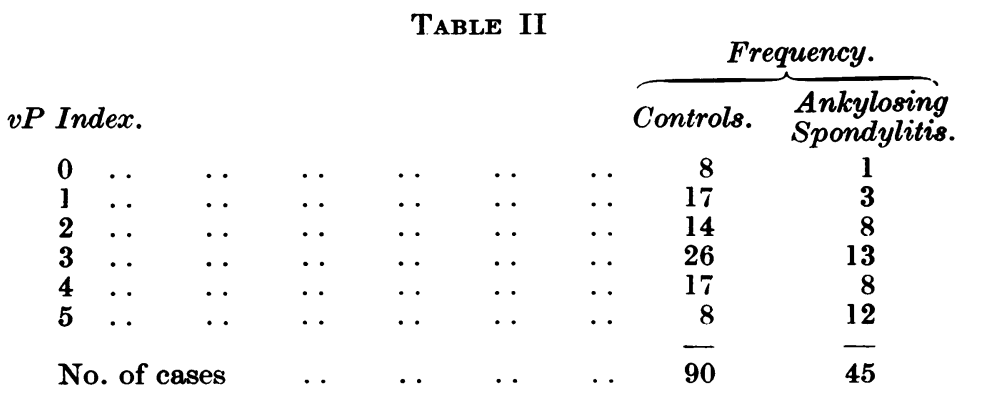

The arithmetic mean for the control group is 2.567 and for the spondylitic group is 3.333 . The standard deviation for the control group is 1.43 and for the spondylitic group is 1.34 .

The standard deviation of the difference between the means-

$$
\begin{aligned}
\sigma & \left.=\sqrt{ } / \frac{(1 \cdot 43)^{2}}{90}+\frac{(1 \cdot 34)^{2}}{45}\right\} \\
& =0 \cdot 25 .
\end{aligned}
$$


Hence the difference between the means

$$
\begin{aligned}
= & 3 \cdot 333-2 \cdot 567 \\
& 0 \cdot 25 \\
= & 3 \cdot 07 \sigma .
\end{aligned}
$$

Reference to probability tables shows that mere chance could produce the difference existing between the means in less than three out of a thousand occasions. One may conclude, therefore (though the number of spondylitic cases is fairly small), that the difference is significant and not due to chance, and that the fact of increased sensitiveness to tuberculin occurring in the spondylitic group is thereby established.*

The control group was composed of the following cases:

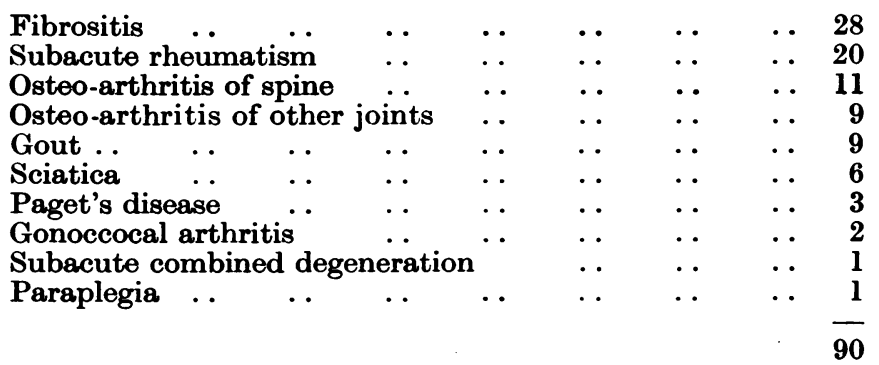

All were ambulant, and nearly all in good condition. Cases of rheumatoid arthritis were excluded, since their general health was impaired and since it was found that their von Pirquet index was low, approximating to that of the females tested, who themselves showed no material difference between rheumatoid and non-rheumatoid levels, as evidenced in Table III.

\begin{tabular}{|c|c|c|c|c|c|}
\hline Groups. & & & $\begin{array}{l}\text { Number } \\
\text { of Cases. }\end{array}$ & $\begin{array}{c}\text { Average } \\
\text { Age. }\end{array}$ & $\begin{array}{c}\text { Average } \\
v P \text { Index. }\end{array}$ \\
\hline $\begin{array}{l}\text { Male rheumatoid arthritis } \\
\text { Female \#" } \\
\text { Other female rheumatics }\end{array}$ & $\begin{array}{l}\cdots \\
\cdots \\
\cdots\end{array}$ & $\begin{array}{l}\ldots \\
\cdots \\
\cdots\end{array}$ & $\begin{array}{l}19 \\
44 \\
53\end{array}$ & $\begin{array}{l}43 \cdot 3 \\
43 \cdot 8 \\
42 \cdot 6\end{array}$ & $\begin{array}{l}2 \cdot 1 \\
2 \cdot 0 \\
1 \cdot 9\end{array}$ \\
\hline
\end{tabular}

TABLE III

* Grateful acknowledgment is due to Dr. Duncan Black, University College of North Wales, for checking this calculation. 
Thus the two diseases, ankylosing spondylitis and rheumatoid arthritis, which show a number of similarities, are contrasted in respect of their tuberculin reactions.

One patient in the spondylitic group had undergone orchidectomy fifteen years before (cause not ascertained). In the male control group, three gave histories of possible tuberculosis in themselves and five in their families. No clinical evidence of tuberculosis was present in any patient tested.

In order to investigate the tubercular specificity, or otherwise, of the spondylitic skin reaction to tuberculin, the evidence of the tuberculin complement fixation test as to the presence

TABLE IV

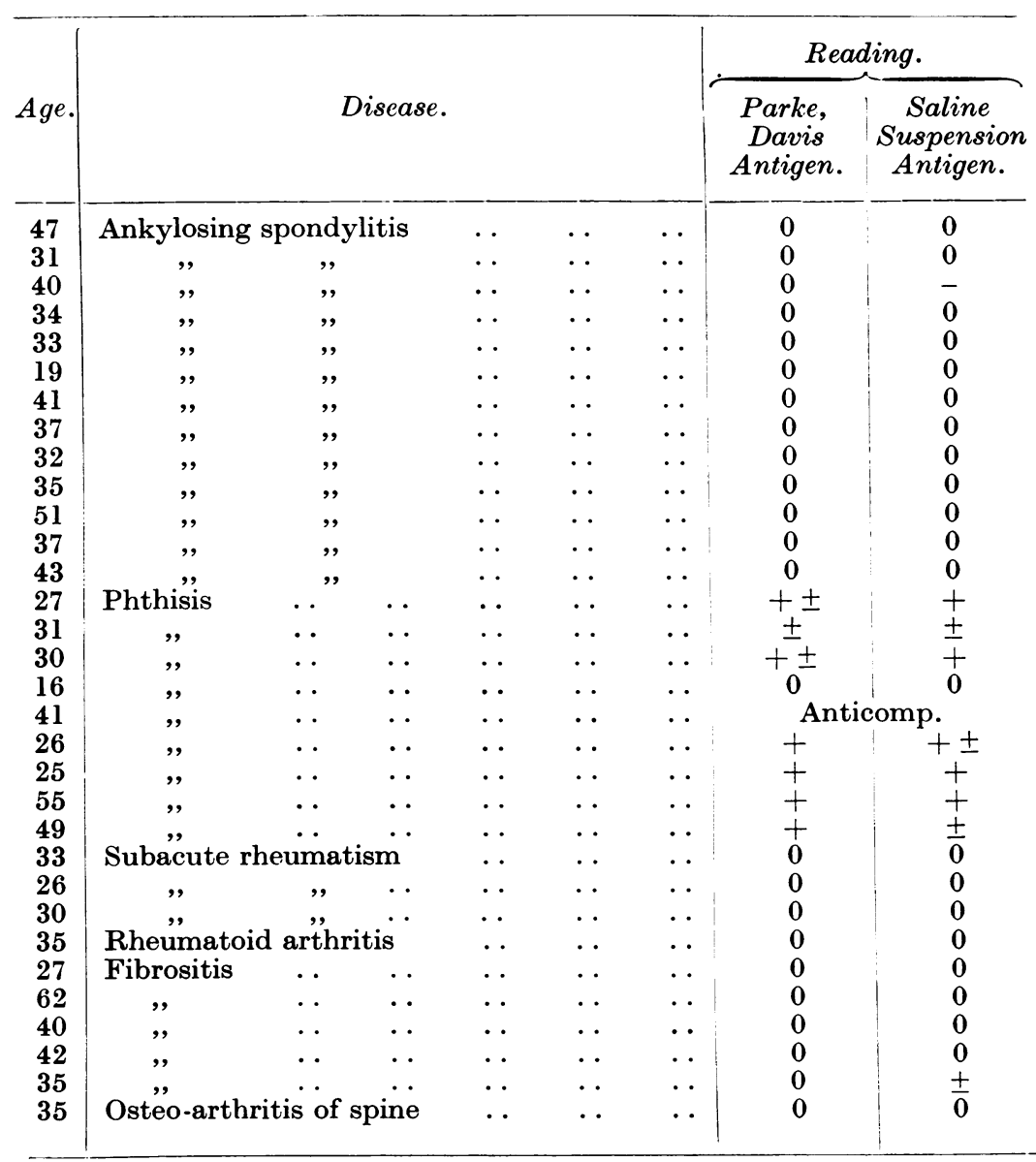


or absence of actively antigenic tubercle was employed. Each serum was given two separate tests on the same day: one with Parke, Davis* antigen and one with a saline suspension of a strain recently isolated from sputum and killed by steaming. The tests were based on the M.R.C. No 1 method for the Wassermann and proved conservative, no strong positive $(++)$ readings being obtained. They were discontinued after thirteen out of thirteen clear negatives had been obtained from the sera of spondylitics, and seven out of nine positives from the sera of phthisis patients. $\dagger$ Table IV. (p. 44) gives the readings.

The results of the von Pirquet and complement fixation tests combine, therefore, to indicate a tuberculin sensitivity which may not be specifically tubercular in spite of the fact that typical and not pseudo skin reactions occurred, and in spite of the fact that control experiments with $B$. coli " tuberculin" (i.e., concentrated glycerine broth culture of this organism) failed to elicit abnormal responses. Nor could the strength of the tuberculin reaction be correlated with any other factor in the course of ankylosing spondylitis, except, imperfectly, with the patient's level of health: those whose constitutions were most impaired, and among whom loss of flesh (but not necessarily of function) was greatest, comprise the majority of the sensitive class.

\section{Discussion}

Evidence explaining the above results is not forthcoming. They might reflect either a non-specific irritant in the tuberculin or a subclinical tubercular state in the patient. The only form of subclinical tuberculosis recognised is the immunising infection of young adults ; and it is not impossible that a more intense tubercular baptism than normal might predispose some cases to the inheritance of spondylitis. Previous histories of subacute rheumatism and of spinal fracture are not uncommon in ankylosing spondylitis; fluorine poisoning ${ }^{3}$ can cause an identical bony buttressing of the column; and cases of Paget's disease (one in the present series) are known to have occasionally developed typical bamboo spines. All these conditions, together with the healing of tuberculosis, involve change in calcium metabolism ; and one of the most essential of early signs in ankylosing spondylitis is decalcification of bone.

* Given by the firm.

† Kindly supplied by Dr. Capes of Bishopstoke Sanatorium. 
SUMMARY

1. The tuberculin sensitiveness of forty-five patients with ankylosing spondylitis has been found to be 30 per cent. higher than that of ninety rheumatic control cases.

2. This result is statistically significant since there is only a 0.3 per cent. chance of its being due to random sampling.

3. Negative tubercular complement fixation reactions in thirteen cases of the disease show that the skin reaction has no background of actively antigenic tubercle detectable by this test.

\section{REFERENCES}

1. Buckley, C. W.: "Reports on Chronic Rheumatic Disease," No. 1. H. K. Lewis, London, 1935.

2. Topley, W. W. C., and Wilson, G. S.: "The Principles of Bacteriology and Immunity." Edward Arnold, London, 1937.

3. Rоноцм, KAJ: "Fluorine Intoxication." H. K. Lewis, London, 1937. 